\title{
A Study of the Effect of Structured Exercise Programme on the Resting Heart Rate of Female Workers at the University of Lagos, Nigeria
}

\author{
Rasheed Kola Ojikutu (Corresponding author) \\ Department of Actuarial Science and Insurance \\ University of Lagos, Lagos, Nigeria \\ E-mail: ladiojikutu@yahoo.com \\ Nkechi Agbaraji \\ Department of Physical and Health Education \\ University of Lagos, Lagos, Nigeria \\ E-mail: nkiaRbaraji@yahoo.com
}

Received: December 6, 2011 Accepted: January 4, 2012 Published: March 1, 2012

doi:10.5539/jms.v2n1p115 URL: http://dx.doi.org/10.5539/jms.v2n1p115

\begin{abstract}
The present study is aimed at assessing the various cardiovascular changes in the female staff of University of Lagos as a result of structured exercise programme. The study examines whether pre-exercise resting heart rate of these workers is more than the post exercise resting heart rate. Using experimental research method, a treatment variation was administered on the experimental and control groups and the effect of the treatment was determined. Questionnaire which identified the age, sex, family health history and pre-participation health screening test was administered. Descriptive statistics which include measures of central tendency, measures of deviation and percentages were used in presenting the data collected. One-way Analysis of Variance (ANOVA) and $\mathrm{t}$-test were used to test the hypotheses. All hypotheses were tested at 0.05 level of significance. Furthermore, two regression models were fitted to confirm the significance of the difference of the pre-test and post-test exercise resting heart rate of the participants The finding revealed that structured exercise programme has a significant effect on the resting systolic and diastolic blood pressures and the resting heart rate of the participants. There is evidence that structured exercise programme had effect on the blood sugar level of the participants and also aids the management of the older adults by keeping them fit, thereby prolonging the effects of aging in the development of cardiovascular disease.
\end{abstract}

Keyword: Cardiovascular, Structured, Exercise, Programme, Female

\section{Background of the study}

Cardiovascular disease (CVD) especially coronary heart disease (CHD) and stroke is the leading killer in developed countries and its prevalence is gradually increasing in developing countries of which Nigeria is not an exception. Quoting from the World Health Report (1999), Ojikutu (2009) explained that taken together, non-communicable diseases contributed about 59 per cent of global mortality (31.7 million deaths) and 43 percent of global burden of disease in 1998 and that over 17 million people are killed yearly by cardiovascular disease. Further, Yusuf et al (2002) in Ojikutu (2009) projected that by 2025; over 80 percent of all cardiovascular diseases in the world will occur in low income and medium countries.

A nation develops a higher standard of living so does death from cardiovascular disease increase (Agostino \& Graham, 2007). This is attributed to the use of automated devices in place of physical work. It has been observed that human organism needs movement and activity to grow, develop and maintain health but with advances in modern technology, physical exertion in daily life has almost been completely eliminated. The automated society in which we live no longer provides us with enough activity to ensure adequate health (US Center for Disease Control and Prevention and American College of Sports Medicine, 1993). 
In Nigeria, there is increase awareness on the dangers of certain lifestyle; however, people still indulge in activities that increase the incidence of cardiovascular diseases (Otinwa, 2008). Tobacco use, high blood cholesterol, high blood pressure and sedentary lifestyle are modified risk factors that have been linked to cardiovascular diseases. Hypertension caused by high blood pressure is another risk factor for heart diseases and is an important risk factor for stroke. Diabetes increases the risk of developing cardiovascular diseases. Individuals with diabetes, depending on gender are more likely to die of coronary heart disease and stroke than individuals without diabetes (Hedelin, 2000). Decreasing the incidence of modified risk factors also decreases the risk of cardiovascular diseases.

Risk factor identification and prudent modification where possible improves an individual's chances of avoiding cardiovascular diseases thereby maintaining good cardiovascular health. For instance, data gathered from physical activities have been shown to aid the reduction of risk factors for cardiovascular diseases. Thomas \& Lafontaine (1998), observed that the impact of exercise on lipid levels can be both transient which is a last bout effect from a single bout of exercise and chronic which is a consistent adaptation resulting from exercise training. All these decrease total triglyceride level, total cholesterol and low density lipoprotein within twenty four to forty eight hours following vigorous aerobic exercise and increase high density lipoprotein.

Wood \& Stefanik (1990) observed that individuals that are active showed lipid profiles indicating a reduced risk for coronary heart disease. This is true for total cholesterol which is lower in more active individuals than inactive ones arid high density lipoprotein which is higher in active individuals than non-active ones. There is also evidence of difference in low density lipoprotein between active and non active individuals.

There is a direct impact of exercise training on the process of atherosclerosis. A study by Schuler, Hainbrecht, Schlierf, Niebauer, Haver, Neumann, Hoberg \& Drinkmann (1992), indicated that individuals who were placed on low fat diet and a high-intensity daily aerobic exercise programme showed regression in their coronary atherosclerotic lesion than the controlled group who were advised to eat less fat and exercise regularly. This assertion was supported by studies of (Froelicher 1990, Lafontaine 1994, Stefanik 1999).

Thomas \& Lafontaine (1998), maintained that individuals who participated exclusively in anaerobic training programmes including dynamic resistance training appear to have lipid profiles similar to those of untrained individuals.

The appropriate use of physical activity is considered an essential element in the non-pharmacologic therapy of elevated serum cholesterol. This statement was supported by sufficient evidence gathered from exercise training results (US Department of Health and Human Services 1991). Physical activity has been advised to be used in conjunction with low-fat diet in order to improve weight loss. Regular physical activity along with body weight or fat loss restores near-normal glucose tolerance and increase insulin sensitivity in individuals with Type 2 diabetes (El-Sayed, Sale, Jones \& Chester 2000).

Kelley (1999) opined that one of the acute effects of sub maximal dynamic endurance exercise is an increase in non-insulin dependent uptake of glucose into the active skeletal muscle and that the effect continues after the activity while the depleted stores of glucose as glucogen is restored.

Acute exercise has been discovered to have a significant effect on individuals at high risk for developing hypertension because of genetics, body composition, primary disease status or high blood pressure by reducing the risk through participation in an endurance training programme. Blood pressure was also found to respond quickly to exercise training and the reduction occurs within three weeks to three months after the start of the training (Ferguson, Bernier, Bauta, Yu-Yahiro \& Schoomaker 2000).

It has been observed that physical activities bring about beneficial changes that limit the progression of metabolic syndrome X with or without changes in total body weight and composition (Welk \& Blair 2000).

Increased physical activity exerts potent and direct effects on other risk factors. It reduces blood lipid levels, lowers blood pressure, improves pulmonary function, normalizes glucose metabolism, alleviates tension and stress, decreases body fat levels and improves uric acid levels and all these changes contribute to lower overall cardiovascular disease risk. This substantiates what was stated by Shephard (1999) that maintenance of physical fitness through physical activity throughout life provides significant protection from cardiovascular disease risk factors and occurrence of actual disease. A nine-year study of Californians showed that sedentary men and women died prematurely at twice the rate compared to counterparts that exercise frequently (Shephard, 1995). Those that reported mild exercise experienced better health than those who remained sedentary. 
The present study is aimed at assessing the various cardiovascular changes in the female staff of University of Lagos as a result of structured exercise programme. The study examines whether pre-exercise resting heart rate of these workers is more than the post exercise resting heart rate.

\section{Methodology}

The method adopted for this study was experimental research method. A treatment variation was administered on the experimental group and control group and the effect of the treatment was determined. Questionnaire which identified the age, sex, family health history and pre-participation health screening test was administered. The questionnaire assisted in identifying the demographic characteristics of the participants and their readiness to participate in the treatment variation. The pre-participation screening test was administered using a physical activity readiness questionnaire (PARQ). The height, weight, systolic and diastolic blood pressure, resting heart rate values, waist and hip circumference measurement of the participants were taken. The blood samples of the participants were taken to determine their blood sugar level which identifies whether they are predisposed to diabetes. The fasting blood sugar level was determined using an accu-check Advantage Model CE 0088 manufactured in Germany.

The research design employed for the study was pre-test post-test randomized groups design (Thomas \& Nelson, 2001). The groups were randomly formed but both groups were given a pretest as well as a posttest.

The groups were exposed to treatment variation at different times during the experiment. The treatment variations were riding on bicycle ergometer, walking and running on a treadmill and different types of flexibility exercises on the floor. After all the structured exercise programme session have been completed, the column mean for the variation $\mathrm{X}$ was computed. The column mean represents the average score for the group.

\subsection{Population}

The population for this study comprised female staff of University of Lagos. The sample was drawn from the population of 883 female staff that responded to the advertisement on the University radio station and Campus News Vol. XIX. No 100 of March 26, 2010. A register was opened at the main bowl of the University of Lagos Sports Centre, the registration was carried out for three days, At the close of the registration period, the participants that turned up for the measurement and administration of questionnaire were one hundred and eighty six. The questionnaire was administered to this group of people and the pretest measurements taken. At the end of the measurement, one hundred and eighty two participants that have predisposing tendency to cardiovascular diseases were subjected to eight (8) weeks structured exercise programme. During the course of the exercise programme, some of the participants dropped out for various reasons such as much work to be done in the office. At the end of the whole exercise, one hundred and eighty female staff who had complete data were used for final data collection and analysis.

\subsection{Research materials and instrument}

The following materials and instruments were used for this study:

1). Automatic blood pressure monitor - Omron digital blood pressure monitor model HEM-712C rating; DC $6 \mathrm{~V} 4 \mathrm{~W}$, clinically validated for accuracy was used to determine the participants' resting blood pressure values which include systolic, diastolic and heart rate.

2). Health scale and height machine model ZT-120 was used to measure the participants' weight and height respectively to determine the body mass index.

3). Tailor's measuring tape graduated in centimeters was used to measure the waist and hip circumference in order to determine the waist - hip ratio.

4). Questionnaire which is made up of three sections that include Section A personal data, Section B pre-participation screening test and Section $\mathrm{C}$ family health history was given to the participants in order to get information on their personal data, contraindications to exercise and family health history.

5). Accu-check ${ }^{\mathrm{R}}$ Advantage II Meter Model CE0088 was used to determine the pretest and posttest fasting blood sugar level of the participants.

6). Accu-check Advantage II test strips which has an electrode with silver coloured bars are inserted up and towards the meter, a yellow window where the sample blood is applied and a comfort curve through which sample of blood enters the strips. The sugar level in the blood plasma indicates automatically on the accu-check advantage meter. 
7). Cotton wool/methylated spirit - these were used for cleaning the fingertips before pricking and after to make sure that the blood clots at the point of puncture.

8). Accucheck ${ }^{R}$ softclix lancet and accu-chek lancing device CE0088 were used to puncture the fingertip in order to collect blood sample.

9). Bicycle ergometer was used for assessment. The participants were made to ride on the bicycle ergometer (Technology Bikerace HC600 made in Italy) for twenty minutes before proceeding to another test.

10). Treadmill model was used for the assessment. The participants were made to walk and run on the treadmill for few minutes.

11). Skipping rope and mats were used for the assessment. The mats were used to do some flexibility exercises on the floor.

12). Stop watch with digital display of seconds and minutes was used to check the time.

Pilot study was conducted before the main study. Ten participants were used for the pilot study. The pilot study assisted in validating the research instrument and identifying likely problems that could be encountered in the process of data collection.

\subsection{Questionnaire administration}

Questionnaires were given to the participants who were medically certified fit to undertake the test from their response in the pre-participation screening test contained in the questionnaire given to them. The questionnaire elicited information on the personal data, pre-participation readiness and the family health history. It was made clear to the participants that an individual is free to quit the test whenever she becomes uncomfortable. Detailed explanation and demonstration of the test preceded actual performance of test.

The participants were advised to adopt behaviour strategies which include self-monitoring and stimulus control. Self-monitoring requires an individual to observe and document her weight, dietary behaviour and exercise pattern. The variables tested were height, weight which were used to determine the body mass index (BMI), waist and hip circumference in centimeters to determine the waist-hip ratio and the resting systolic, diastolic blood pressures, the resting heart rate and fasting blood sugar level, These variables were determined before the commencement of the exercise programme and after the structured exercise programme.

The participants worked within $60 \%$ to $70 \%$ of their exercise intensity. The exercise intensity was determined using the straight percentage heart rate method. In this technique, exercise training heart rate was calculated as a percentage of maximal heart rate. Maximal heart rate is estimated using the formula 220 - age (Wasserman, Hansen, Sue, Whipp \& Casaburi, 1994). If a participant would train at about $60 \%$ to $70 \%$ intensity and is 35 years, her exercise training heart rate is thus derived. Therefore, given

$$
\text { Age }=35
$$

$$
\text { Peak heart rate }=220-35=185(\text { maximal heart rate })
$$

Exercise intensity lower limit $=60 \%$

$$
\text { Exercise intensity upper limit }=70 \%
$$

Exercise training heart rate is computed thus:

$$
\begin{aligned}
& \text { Lower limit }=\text { Peak heart rate } \times 0.6=185 \times 0.6=111.0 \\
& \text { Upper limit }=\text { Peak heart rate } \times 0.7=185 \times 0.7=129.5
\end{aligned}
$$

In the stated example, the subject will work within 130 and 167 beats per minute.

\subsection{Height and weight determination}

The height machine model ZT-120 and the health scale were used to measure the height and weight respectively. Height was taken in meters and the weight in kilogrammes without any footwear or any object hanging on the body. The participants were instructed to step on the scale with the hands freely hanging by the sides and looking straight before the scale was read. Allowance of $0.1 \mathrm{~kg}$ was made for clothing on the measurement of every participant. The height and weight measurement were used to determine the Body Mass Index (BMI) of the participants. This was taken before the structured exercise programme and after the exercise programme.

$$
\mathrm{BMI}=\frac{\text { Weight in } \mathrm{kg}}{(\text { Height in } \mathrm{m})^{2}}
$$




\subsection{Determination of the resting blood pressure and heart rate}

The resting heart rate and blood pressure values of the participants were taken before and after the exercise programme with automatic blood pressure monitor, Omron ${ }^{\mathrm{R}}$ digital blood pressure monitor model HEM -712 C. The participants were allowed ten minutes rest before the measurements were taken.

\subsection{Waist - hip ratio determination}

The waist circumference was taken at the point of minimal abdominal girth just below the rib cage and slightly above the top of the hipbone. The hip measurement is taken at the symphysis surfaces of the pubic bones in front and at the outermost protrusion of the buttocks at the back. At the time of the measurement, the feet were together. The hip measurement was used to divide the waist measurement to get the waist hip ratio.

$$
\text { Waist-hip ratio }=\frac{\text { Waist in } \mathrm{cm}}{\text { Hip in } \mathrm{cm}}
$$

The waist-hip ratio is a measure of regional fat distribution, the score will determine who is at an increased risk of becoming obese,

\subsection{Determination of blood sugar level}

Blood sample for the determination of the blood sugar level was withdrawn from the finger tip following the procedure specifically outlined in the user's manual. Blood sugar level was determined using an Accu-chek advantage II meter model CE 0088 and test strip. After the test strip has been inserted into the meter, the finger tip was cleaned and pricked using the softclix pro lancing device and softclix pro lancets. The yellow part of the test strips was completely filled with the blood. When blood is applied to strip, an hour glass flashes on the meter display until measurement is completed. The result will display on the meter automatically in $\mathrm{mg} / \mathrm{dL}$ or $\mathrm{MmoL} / \mathrm{L}$. The test strip was removed from the meter and discarded along with the lancet in a dust bin. A new test strip and lancet were used for each individual.

\subsection{Determination of the cardiovascular changes following structured exercise programme}

After the measurement of the variables, the participants were subjected to structured exercise programme to determine the various changes that will occur within the cardiovascular system. The study adopted a graduated exercise test of riding on a bicycle ergometer for 20 minutes, with 5 minutes rest, walking and running on a treadmill for 20 minutes with 5 minutes rest and flexibility exercise or stretching exercises for 10 minutes for the exercise protocol. This protocol is repeated at every exercise session that lasted for 60 minutes for 3 times in a week. The bicycle ergometer was adjusted to a height that produced a slight bend at the knee joint, this assisted to test their muscular endurance. A stop watch was used to make sure that the accurate time was kept. After 20 minutes ride on the bicycle ergometer which started from a gradual process, the participants were allowed 5 minutes of rest to walk around and stretch their legs. The treadmill's speed was gradually increased and it automatically displayed the heart rate, the meters covered per minute and the time. When it reached 20 minutes, the treadmill was stopped and they had 5 minutes of rest. The final stage of the exercise was the stretching exercise on the floor with the use of a mat. Stretching exercises like static stretch, ballistic stretch and proprioceptive neuromuscular facilitation (PNF) exercise were used. This lasted for 10 minutes.

\section{Statistical tools}

The descriptive statistics which includes measures of central tendency, measures of deviation and percentages were used in presenting the data collected. One-way Analysis of Variance (ANOVA) and t - test were used to test the hypotheses. All hypotheses were tested at 0.05 level of significance.

Two regression models were fitted to confirm the significance of the difference of the pre-test and post-test exercise resting heart rate of the participants. The model is as stated below.

\subsection{The model}

To confirm the significance of the difference of the pre and post exercise resting heart rates of the participants, two regression models were fitted, one for the pre-exercise scores and the other for the post-exercise scores. The Estimated Resting Heart Rate of the individuals were calculated for each of the models and the two estimates were compared. If the estimate for the pre-exercise heart rate is less than the estimate for the post-exercise heart rate, then it will be concluded that truly the exercise plays significant role in reducing resting heart rate. Furthermore, the hypotheses were tested to show the significance of this difference using the paired comparison t-test. 
Let $Y_{i j}$ be the resting heart rate of the $\mathrm{i}^{\text {th }}$ individual in State $\mathrm{j}$.

Where $i=1,2,3 \ldots 180$ and $j=0,1$ where 0 denotes the pre-exercise state of the $i^{\text {th }}$ individual and 1 denotes the post-exercise state of the $\mathrm{i}^{\text {th }}$ individual.

The model assumes that $\mathrm{y}_{\mathrm{ij}}=\mathrm{f}(\alpha, \mathrm{X} \quad \mathrm{kij}, \mathrm{k}=1,2 \ldots .10, \varepsilon)$ where $\mathrm{k}$ is the index for the $\mathrm{k}^{\text {th }}$ variable.

Let

$\mathrm{X}_{1 \mathrm{ij}}$ be the height; $\mathrm{X}_{2 \mathrm{ij}}$ be the weight; $\mathrm{X}_{3 \mathrm{ij}}$ be the BMI; $\mathrm{X}_{4 \mathrm{ij}}$ be the systolic blood pressure; $\mathrm{X}_{5 \mathrm{ij}}$ be the diastolic blood pressure; $X_{6 i j}$ be the waist measure; $X_{7 i j}$ be the hip measure; $X_{8 \mathrm{ij}}$ be the waist-hip ratio; $X_{9 \mathrm{ij}}$ be the fasting blood sugar of the ith individual in State $\mathrm{j}$ and $\mathrm{X}_{10 \mathrm{ij}}$ be the age of the ith individual.

Therefore

Equation (1) is

$$
\begin{aligned}
& \mathrm{Y}_{10}=\alpha+\beta_{\mathrm{Iio}} \mathrm{X}_{\mathrm{lij}}+\beta_{20} \quad \mathrm{X}_{2 \mathrm{i} 0}+\beta_{30} \mathrm{X}_{3 \mathrm{i} 0}+\beta_{40} \quad \mathrm{X}_{4 \mathrm{i} 0}+\beta_{50} \mathrm{X}_{510}+\beta_{60} \quad \mathrm{X}_{6 \mathrm{i} 0}+\beta_{70} \quad \mathrm{X}_{7 \mathrm{i} 0}+ \\
& \beta_{80} \quad X_{8 i 0}+\beta_{9 i 0} \quad X_{9 i 0}+\beta_{10,0} X_{10,10}+\varepsilon
\end{aligned}
$$

and

Equation (2) is

$$
\begin{aligned}
& Y_{\text {il }}=\alpha+\beta_{1 \mathrm{i}} \quad \mathrm{X}_{\mathrm{lij}}+\beta_{2} \quad \mathrm{X}_{2 \mathrm{i} 1}+\beta_{1} \quad \mathrm{X}_{3 \mathrm{i}}+\beta_{4} \quad \mathrm{X}_{4 \mathrm{ii}}+\beta_{5} \quad \mathrm{X}_{5 \mathrm{i}}+\beta_{6} \quad \mathrm{X}_{6 \mathrm{i}}+\beta_{7} \quad \mathrm{X}_{7 \mathrm{i}}+\beta_{8} \quad \mathrm{X}_{8 \mathrm{i}}+\beta_{9} \quad \mathrm{X}_{9 \mathrm{i}}+\beta_{10} \\
& \mathrm{X}_{10,1}+\varepsilon
\end{aligned}
$$

The model intends to show that $y_{i l}-y_{i o}<0$ for all $i$ where $y_{i l}$ and $y_{i 0}$ are estimated values of $y_{i l}$ and $y_{i 0}$ respectively.

\subsection{Data analysis}

Data collected from the 180 participants that had complete information were statistically analyzed and the results are presented below.

\section{Insert Table 1 here}

Table 1 shows that $50 \%$ of the participants weigh more than $87 \mathrm{~kg}$ (Median before exercise $=87 \mathrm{~kg}$ ) before the exercise with many in the group weighing $86 \mathrm{~kg}$ (Mode before exercise $=86$ ). After the exercise, many of the participants had their weights reduced to $78 \mathrm{~kg}$ (Mode after exercise $=78$, median after $=86.23$ ). The reduction of mode from $86 \mathrm{~kg}$ to $78 \mathrm{~kg}$ may be an indication of the possibility of the effect of the structured exercise programme on the participants. The aforementioned conclusion is supported by the noticeable reduction in the mean weight from $89.87 \mathrm{~kg}$ before the exercise to $86.23 \mathrm{~kg}$ after the exercise.

\section{Insert Table 2 here}

Table 2 shows that before the exercise the mean resting systolic blood pressure (RSBP) was $155.14 \mathrm{mmHg}$. After the exercise, the mean RSBP reduced to $149.96 \mathrm{mmHg}$. Moreover, the participants have pre-test resting systolic blood pressure of $170 \mathrm{mmHg}$ (Mode $=170$ ) which is an indication that many of the participants have predisposing tendency to hypertension. Although after the exercise, the mean resting systolic blood pressure reduced to $149.97 \mathrm{mmHg}$ while many of the participants still have post resting systolic blood pressure of $170 \mathrm{mmHg}$ (i.e. Mode RSBP was not altered despite the exercise).

\section{Insert Table 3 here}

The pre-test resting diastolic blood pressure (DBP) as indicated in table 3 showed that the participants had mean of $85.2 \mathrm{mmHg}$ with many of the participants having $80 \mathrm{mmHg}$ (Mode $=80 \mathrm{mmHg}$ ). After the exercise, the mean reduced to $81.56 \mathrm{mmHg}$ with many of them having $78 \mathrm{mmHg}$. This may be an indication that there is the possibility of the exercise programme having effect on the resting diastolic blood pressure.

\section{Insert Table 4 here}

From table 4, the mean resting heart rate (RHR) was $90.44 \mathrm{bpm}$ before the structured exercise programme. After the structured exercise programme the mean reduced to $86.8 \mathrm{bpm}$. This indicates the possibility of the effect of exercise progamme on the participants' resting heart rate. It is noticeable that the modal RHR which was 80.Oobpm did not change after the exercise.

Insert Table 5 here 
Table 5 shows that the mean of the pre-exercise measurement of waist reduced from $79.26 \mathrm{~cm}$ to 76.01 after the exercise. Although many of the participants still have $80 \mathrm{~cm}$ circumference after the exercise, the reduction in mean may be the possibility of the effect of the structured exercise programme.

\section{Insert Table 6 here}

In table 6, the participants' mean hip in centimeters reduced from 87.0 to 83.35 and mode reduced from 100 to 90 which shows that while many of the participants had hip in centimeters of 100 before the exercise, this was reduced to 90 after the exercise.

\section{Insert Table 7 here}

From table 7, it will be observed that the mean fasting blood sugar level reduced from $127 \mathrm{mg} / \mathrm{dI}$ before the exercise to $119.78 \mathrm{mg} / \mathrm{dI}$ after the exercise. Moreover, while over $50 \%$ of the participants had blood sugar level of $126 \mathrm{mg} / \mathrm{dI}$ before the exercise, this was reduced to $121 \mathrm{mg} / \mathrm{dI}$ after the exercise. This may be an indication that the structured exercise programme may have had the desired effect on many of the participants' fasting blood sugar level. However, it should be mentioned that while many of the participants had fasting blood sugar level of $120 \mathrm{mg} / \mathrm{dI}$ before the exercise, this changed to $140 \mathrm{mg} / \mathrm{di}$ after the exercise.

\section{Insert Table 8 here}

Table 8 shows that the mean height of the participants is $1.63 \mathrm{~m}$ and the mean age is 52.44 yrs. It could also be observed that many of the participants that are 51 years old have heights between $1.58 \mathrm{~m}$ and above.

\section{Insert Table 9 here}

Table 9 shows the descriptive statistics of mean and standard deviation according to age group of the pre-test and post-test of the fasting blood sugar level of the participants. From the table, the age group 58 and above presents the highest number of participants and all the age groups had the fasting blood sugar level reduced which may be an indication of the effect of exercise on the fasting blood sugar level of the participants.

\section{Insert Table 10 here \\ Insert Table 11 here \\ Insert Table 12 here}

$\mathrm{R}^{2}=0.676$ which means that $67.6 \%$ of the variation observed in the resting heart rate of the participants is explained by the ten predictor variables in the model i.e. $\mathrm{X}_{\mathrm{kij}}, \mathrm{k}=1-10$.

Table 12 showed that the model is significant $(\mathrm{F}=35.232, \mathrm{p}<0.05)$. Therefore, the model in this case is

$$
\begin{gathered}
\mathrm{Y}_{\mathrm{io}}=99.051-17.132 \mathrm{X}_{1 \mathrm{ij}}+0.044 \mathrm{X}_{2 \mathrm{ij}}-0.838 \mathrm{X}_{3 \mathrm{ij}}-0.661 \mathrm{X}_{4 \mathrm{ij}}+0.390 \mathrm{X}_{5 \mathrm{ij}}-0.664 \mathrm{X}_{6 \mathrm{ij}}+0.770 \mathrm{X}_{7 \mathrm{ij}}+90.093 \\
\mathrm{X}_{8 \mathrm{ij}}-0.019 \mathrm{X}_{9 \mathrm{ij}}+0.369 \mathrm{X}_{10 \mathrm{ij}} \\
\text { Insert Table } 13 \text { here } \\
\text { Insert Table } 14 \text { here }
\end{gathered}
$$

$\mathrm{R} 2=0.697$ which means that $69.7 \%$ of the variation observed in the resting heart rate of the participants is explained by the 10 predictor variables in the model i.e. $\mathrm{X}_{\mathrm{Kij}}=1-10$.

Table 14 showed that the model is significant $(\mathrm{F}=38.905, \mathrm{p}<0.05)$. Therefore, the model in this case is

$$
\begin{gathered}
\mathrm{Y}_{\mathrm{il}}=107.269+8.087 \mathrm{X}_{1 \mathrm{ij}}-0.197 \mathrm{X}_{2 \mathrm{ij}}-0.210 \mathrm{X}_{3 \mathrm{ij}}-0.703 \mathrm{X}_{4 \mathrm{ij}}+0.291 \mathrm{X}_{5 \mathrm{ij}}+0.184 \mathrm{X}_{6 \mathrm{ij}}+0.131 \mathrm{X}_{7 \mathrm{ij}}+19.894 \\
\mathrm{X}_{8 \mathrm{ij}}+0.014 \mathrm{X}_{9 \mathrm{ij}}+0.457 \mathrm{X}_{10 \mathrm{ij}} \\
\text { Insert Table } 15 \text { here }
\end{gathered}
$$

Table 15 tests the significance of the difference of the pre and post- exercise scores and it shows that the difference is significant $(\mathrm{t}=-26.741, \mathrm{P}<0.05)$. This clearly shows that the exercise is effective in the reduction of pre-resting heart rate.

\section{Discussion}

The aim of the present study was to examine the cardiovascular changes following structured exercise programme among female staff of University of Lagos.

The physical characteristics of the participants of this study are similar to the female participants used by Otinwa (2004, 2005 \& Anderson, 1999) in their studies. The participants used by these researchers had mean weight, height and body mass index (BMI) of $68.67 \mathrm{~kg}, 67.62 \mathrm{~kg}$ and $74.01 \mathrm{~kg}, 1.66 \mathrm{~m}, 1.59 \mathrm{~m}$ and $1.64 \mathrm{~m}$ and $25.73 \mathrm{~kg} / \mathrm{rn} 2$, $24.67 \mathrm{~kg} / \mathrm{rn} 2,27.86 \mathrm{~kg} / \mathrm{m} 2$ body mass index respectively. The mean resting heart rate value observed in this study 
are similar to those reported by Astrand (2001), Otinwa, Phillips \& Mbakwem (2006), Otinwa \& Agbaraji (2008) for females. The mean systolic blood pressure observed in this study was similar to those reported by Israel, Sullivan \& Marks (1994) and Blair (1996), for females.

In this study, it was discovered that structured exercise programme had a significant effect on the resting heart rate of the participants. This was seen in the difference between the mean pre-test measurement of $90.44 \mathrm{bpm}$ and post-test of $86.8 \mathrm{bpm}$ of the participants. This is in line with the discoveries of Pollock, Wilmore \& Fox (2005) which stated that the benefits of exercise include decrease in resting heart rate which aid performance of any task or physical activity. This finding is also in agreement with research works carried out by Franklin (1998), Hagberg, (1990 \& 1997) and Emiola (1979) which states that exercise lowers resting heart rate and that it enhances performance.

Results of this study showed that structured exercise programme has a significant effect on the blood sugar level of the participants. This result is in agreement with the discoveries of El-Sayed, Sale, Jones \& Chester (2000) which states that regular physical activity along with body weight or fat loss restores near-normal glucose tolerance and increases insulin sensitivity in individuals with Type II diabetes. It is also in line with the findings of Kelley (1999), which revealed that one of the acute effects of submaximal dynamic endurance exercise is an increase in non-insulin-dependent uptake of glucose into the active skeletal muscle and that the effect continues after the activity while the depleted stores of glucose as glucogen is restored, There is a significant correlation coefficient between pre-test fasting blood sugar level and post-test fasting blood level of the participants in this study. This agrees with the discoveries of Colberg (2001), Grundy, Benjamin, Burke, Chait \& Eckel (1999), Hanson (1993) \& Bouchard, Bray \& Hubbard (2003).

Individuals that have body mass index range of $22-25,25-30,30$ - above and below 20 have been classified as having the lowest risk for chronic diseases, overweight, obesed and underweight respectively (Calle, Thun, Petrelli, Rodriguez \& Health 1999). Flegal, Carrol, Kuezmarski \& Johnson (1998), equally stated that mortality rate was $25 \%$ higher for people with a body mass index of $25-30$ and $50-100 \%$ higher for those with a body mass index of 30 and above. This is in agreement with the discoveries of this study which found that the pre-test measurement of the participants fall within the high risk for chronic diseases for all the age groups with a body mass index of 30 and above. In this study, as the structured exercise programme was applied, the participants showed slight reduction in the body mass index (BMI). The evidence is seen in the mean pre-test body mass index measurement of $34.24 \mathrm{~kg} / \mathrm{rn} 2$ and post-test mean body mass index of $32.85 \mathrm{~kg} / \mathrm{rn} 2$. These discoveries in this study are in line with the discoveries of the research work carried out by Welk \& Blair (2000), Washington (2002), Otinwa (2008), Otinwa \& Agbaraji (2008), Ikulayo (2005), World Health Organization (2000) and Farrel (2002).

The findings of this study revealed that structured exercise programme has a significant effect on the resting systolic and diastolic blood pressures of the participants. This finding is in agreement with the findings of the research work of Primatesta, Brooks \& Poulter (2001), Ferguson, Benier, Bauta, YuYahiro \& Schoomaker (2000), Shephard (1995 \& 1999) and Emiola (2008) which stated that exercise aids greater emptying of the systolic. The structured exercise programme treatment to the participants had an impact on the resting systolic and diastolic blood pressure measurements. The evidence is seen on the pre-test mean resting systolic and diastolic blood pressure measurements of $155.6 \mathrm{mmHg}$ and $85.74 \mathrm{mmHg}$ which reduced to $144.96 \mathrm{mmHg}$ and $81.57 \mathrm{mmHg}$ respectively after the application of the exercise treatment. The result of this research work supports the result of the research work of Wood \& Stefanik (1990) which stated that active individuals showed lipid profiles which is a predisposing factor to hypertension indicating a reduced risk for coronary heart disease. This is in agreement with the findings of Schuler, Hainbrecht, Schlierf, Niebauer, Harer, Neuman, Hoberg \& Drinkmann (1992), Froechcher (1990), Lefontaine (1994) \& Stefanik (1999).

The results of these findings showed evidence indicating that structured exercise programme had effect on the blood sugar level of the participants. It means that age is not a barrier to blood sugar level of the participants. It shows that it can rise in anybody irrespective of age. There is indication that age plays a role in pre-disposing the individuals to cardiovascular diseases especially as the age increases. These findings also support the assertion of Gillis (1995), Superko (2003), American Heart Association (2003) and Williams (2002) which states that proper management of the older adultsinfluence the tendency for the development of cardiovascular diseases among the adults.

Structured exercise programme aids the management of the older adults by keeping them fit, thereby prolonging the effects of aging in the development of cardiovascular disease. This assertion is shown in the reduction of the post-test measurements of resting heart rate, resting systolic blood pressure and resting diastolic blood pressure 
after the structured exercise programme. The findings also showed effect of structured exercise programme on the fasting blood sugar level among the participants which means irrespective of age structured exercise programme can affect anybody at any age positively or negatively in terms of sugar level. This agrees with the findings of the research work of Thomas \& Lafontaine (1998), US Department of Health and Human Services (1991), William (1999), and Turley \& Wilmore (1997).

\section{References}

Agostino, R. B. D., and Graham, I. M. (2007). The primacy of total risk estimation in planning management. In Graham, I. M., Ralph, B. and Agostino, D. (Eds.), Managing cardiovascular risk. Oxford, UK: Clinical Publishing.

Anderson, R. E. (1999). Effects of lifestyle activity versus structured aerobic exercise in obese women. Journal of American Medical Association JAMA, 281: 335. http://dx.doi.org/10.1001/jama.281.4.335

Astrand, I. (2001). Aerobic work capacity in men and women with special reference to age. Acta Physiologica Scandinavica.

Astrand, P. B., Guddy, T. E., Saltin, B., \& Stenberg, J. (2002). Cardiac output during submaximal and maximal work. Journal of Applied Physiology, 19(2): 268 - 274.

Bouchard, C., Bray, G. A., \& Hubband, V. S. (2001). Basic and clinical aspects of regional fat distribution. American Journal of Clinical Nutrition, Vol. 52.

Calle, E. E., Thun, M. J., Pretrelli, Rodriguez, C., \& Health, C. W. (1999). Body mass index and mortality in a perspective cohort of US adults. The New England Journal of Medicine, 341.

Colberg, S. R. (2001). Exercise: A diabetes cure for many? American College of Sports Medicine Health and Fitness Journal, 5(2), 20 - 26.

El-Sayed, M. S., Sale, C., Jones, P. G. W., \& Chester, M. (2000). Blood hemostasis in exercise and training. Journal of Medicine and Science in Sports and Exercise, 32.

Ferguson, F. W., Bernier, J. I., Bauta, G. R., Yutahiro, J., \& Schoomaker, E. B. (2000). Effects of exercise and conditioning on clothing and fibrinolytic activity in men. Journal of Applied Physiology.

Flegal, K. M., Carrol, M. D., Kuezmarski, R. J., \& Johnson, C. L. (1998). Overweight and obesity in the United States: Prevalence and trends. International Journal of Obesity and Related Metabolic Disorders, 22.

Franklin, B. A., and Munning, F. (1998). A common misunderstanding about heart rate and exercise. ACSM's Health and Fitness Journal. [Online] Available: http://www.aafp.org/afp/99041592211. html

Froelicher, V. E. (1990). Exercise, fitness and coronary heart disease. In Bouchard, C., Shephard, R. J., Stephens, T., Sutton, J. R. \& Mcpherson, B. D. (eds), Exercise, fitness and health: A consensus of current knowledge. Champaign, IL: Human Kinetics 429 - 451.

Grundy, S. M., Benjamin, J. J., Burke, G. I., Chait, A., \& Eckel, R. H. (1999). Diabetes and cardiovascular diseases: A statement for healthcare professionals from the American Heart Association. Circulation 100.

Hagberg, B. M. (1990). Exercise, fitness and hypertension. In Bouchard C. Shepherd, Stephens, T., Sutton, J. R. \& McPherson, B. D. (eds.), Exercise fitness and health. Campaign, IL: Human Kinetics 455 - 466.

Hagberg, J. M. (1997). Physical activity, physical fitness and blood pressure. In A. Leon (Ed), Physical activity and cardiovascular health. Champaign Ill: Human Kinetics.

Hedelin, R. (2000). Cardiac autonomic imbalance in an overtrained athlete. Medicine and Science in Sports and Exercise, Vol. 32(9). [Online] Available: http://www.rohan.sdsu.edu/dept/coachsa/ intro. html (January 18, 2007).

Israel, R., Sullivan, M., \& Marks, R. (1994). Relationship between cardiorespiratory fitness and lipoprotein in men and women. Journal of Medical Science, Sports and Exercise, 26, 25 - 431.

Kelly, G. (1999). Dynamic resistance exercises and resting blood pressure in adults: A meta-analysis. Journal of Applied Physiology, 82.

Lafontaine, T. (1994). Preventing the progression of or reversing coronary atherosclerosis. American College of Sports Medic/ne Certified News, 4(3): 1- 6.

Ojikutu, R.K. (2009). Prevalence of Cardiovascular Disease in Lagos State, Nigeria. Ghana Journal of Development Studies, 6(1): 59-75. 
Otinwa, G. O. (2004). Cardiorespiratory fitness of selected Nigeria female adults. The $44^{\text {th }}$ ICHPERSD World Congress Proceedings, June, $26-29$.

Otinwa, G. O. (2008). Achieving wellness lifestyle. Institute of Security. Lagos: Integrity Press Ltd.

Otinwa, G. O. (2008). Controlling the risk factors of obesity and overweight through sports and exercise. Journal of Nigeria Association of Sports Science and Medicine (JONASSM), X(1), 5 - 8.

Otinwa, G. O., and Agbaraji, N. A. (2008). Exercise as an adjunct to weight loss and maintenance in moderately obese females. Journal of Nigeria Association of Sports Science and Medicine (JONASSM), X(1), 67 - 70.

Otinwa, G. O., Phillips, A. O., and Mbakwem C. A. (2006). Cardiorespiratory fitness of University of Lagos female administrators. Journal of International Council for Health, Physical Education, Recreation, Sports and Dance, 1 (1):15 -19.

Pollock, M. L., Wilmore, H., \& Fox, S. M. (2005). Health and fitness through physical activity. New York: John Wiley and Sons, 50: 431 - 450.

Schuler, G. R., Hainbrecht, G., Schlierf, J., Niebauer, K., Haver, J., Neumann, E., Hoberg, A., Drinkmann, F. (1992). Regular physical exercise and low-fat diet: Effects on progression of coronary artery disease. Circulation. 86: $1-111$.

Shephard, R. J. (1995). Exercise and sudden death: An overview. Sports Science Review, 4.

Stefanick, M. L. (1999). Exercise and weight control. Exercise and Sports Science Reviews, 21: 363-396.

Thomas, J. R., and Nelson, J. K. (2001). Research methods in physical activity. (4th Edition). USA: Human Kinetics.

Thomas, T. R., \& Lafontaine, T. (1998). Exercise and lipoproteins. In Roitman, J. I. (ed.), ACSM's resource manual for guidelines for exercise testing and prescription $3^{\text {rd }}$ edition, Philadelphia: Lippincott, Williams and Wilkins 294 - 301.

United States Centre for Disease Control and Prevention and American College of Sports Medicine (1993). Summary statement: Workshop on physical activity and public health. Sports Medicine Bulletin, 28, No. 4.

United States Department of Health and Human Services (2000). Physical activity and health. A report of the Surgeon General. Atlanta. US: Department of Health and Human Services. [Online] Available: www.acsm.org (January 30, 2007).

United States Department of Health and Human Services, Public Health Services, National Institute of Health (1991). Report of the expert panel on blood cholesterol levels in children and adolescents. National Institute of Health Publication No. 91. [Online] Available: http://www.os.dhhs.gov/ (February 20, 2007).

Wasserman, K., Hansen, J., E., Sue, D. Y., Whipp, B. J., and Casaburi, R. (1994). Principles of exercise testing and interpretation. 2 Edition. Philadelphia: Lea and Febiger.

Welk, G. J., \& Blair, S. N. (2000). Physical activity protects against the health risks of obesity. President's Council on Physical Fitness and Sports Research Digest Series, 3 (12).

Wood, P. D., \& Stefanick, M. I. (1990). Exercise, fitness and atherosclerosis. In Bouchard, C., Shephard, R. J., Stephens, T., Sutton, J. R., \& McPherson, B. (Eds), Exercise, fitness and health: A consensus of current knowledge. Champaign, IL: Human Kinetics 409

Table 1. Pre-test and post-test analysis of the participants' weight

\begin{tabular}{|l|c|c|}
\hline & Pre Weight $(\mathrm{Kg})$ & Post Weight $(\mathrm{Kg})$ \\
\hline $\mathrm{N}$ & 180 & 180 \\
\hline Mean & 89.87 & 86.23 \\
\hline Median & 87.0 & 84.0 \\
\hline Mode & 86 & 78 \\
\hline Std deviation & 11.59 & 11.03 \\
\hline Skewness & 11.03 & 0.19 \\
\hline
\end{tabular}


Table 2. Pre-test and post-test analysis of the participants' resting systolic blood pressure

\begin{tabular}{|l|c|c|}
\hline & $\begin{array}{c}\text { Pre Systolic } \\
(\mathrm{mmHg})\end{array}$ & $\begin{array}{c}\text { Post Systolic } \\
(\mathrm{mmHg})\end{array}$ \\
\hline $\mathrm{N}$ & 180 & 180 \\
\hline Mean & 155.14 & 149.96 \\
\hline Median & 157.0 & 150.0 \\
\hline Mode & 170.0 & 170.0 \\
\hline Std deviation & 25.6 & 24.72 \\
\hline Skewness & -1.5 & -1.56 \\
\hline
\end{tabular}

Table 3. Pretest and post-test analysis of the participants' resting diastolic blood pressure

\begin{tabular}{|l|c|c|}
\hline & $\begin{array}{c}\text { Pre-test DBP } \\
(\mathrm{mmHg})\end{array}$ & $\begin{array}{c}\text { Post-test DBP } \\
(\mathrm{mmHg})\end{array}$ \\
\hline $\mathrm{N}$ & 180 & 180 \\
\hline Mean & 85.2 & 81.56 \\
\hline Median & 85.2 & 82.0 \\
\hline Mode & 80.0 & 78.0 \\
\hline Std deviation & 7.99 & 76.9 \\
\hline Skewness & 0.55 & 0.52 \\
\hline
\end{tabular}

Note: RDBP $=$ Resting Diastolic Blood Pressure.

Table 4. Pre-test and post-test analysis of resting heart rate

\begin{tabular}{|l|c|c|}
\hline & $\begin{array}{c}\text { Pre-test RHR } \\
(\mathrm{bpm})\end{array}$ & $\begin{array}{c}\text { Post-test RHR } \\
(\mathrm{bpm})\end{array}$ \\
\hline $\mathrm{N}$ & 180 & 180 \\
\hline Mean & 90.44 & 86.8 \\
\hline Median & 84.0 & 81.0 \\
\hline Mode & 80.0 & 80.0 \\
\hline Std deviation & 24.06 & 23.72 \\
\hline Skewness & 3.05 & 3.03 \\
\hline
\end{tabular}

Note: $\mathrm{RHR}=$ Resting Heart Rate, $\mathrm{bpm}=$ beats per minute

Table 5. The pre-test and post-test analysis of the participants' waist

\begin{tabular}{|l|c|c|}
\hline & $\begin{array}{c}\text { Pre-test Waist } \\
(\mathrm{cm})\end{array}$ & $\begin{array}{c}\text { Post-test Waist } \\
(\mathrm{cm})\end{array}$ \\
\hline $\mathrm{N}$ & 180 & 180 \\
\hline Mean & 79.26 & 76.01 \\
\hline Median & 84.0 & 80 \\
\hline Mode & 80.0 & 80.0 \\
\hline Std deviation & 16.87 & 16.41 \\
\hline Skewness & -1.65 & -1.69 \\
\hline
\end{tabular}


Table 6. Pre-test and post-test analysis of the participants' hip

\begin{tabular}{|l|c|c|}
\hline & $\begin{array}{c}\text { Pre-test Hip } \\
(\mathrm{cm})\end{array}$ & $\begin{array}{c}\text { Post-test Hip } \\
(\mathrm{cm})\end{array}$ \\
\hline $\mathrm{N}$ & 180 & 180 \\
\hline Mean & 87.0 & 83.35 \\
\hline Median & 90.0 & 88.0 \\
\hline Mode & 100.0 & 90.0 \\
\hline Std deviation & 17.64 & 16.75 \\
\hline Skewness & -1.51 & -1.61 \\
\hline
\end{tabular}

Table 7. Pre-test and post-test analysis of the participants' fasting blood sugar level (FBSL)

\begin{tabular}{|l|c|c|}
\hline & $\begin{array}{c}\text { Pre-test FBSL } \\
(\mathrm{Mg} / \mathrm{dl})\end{array}$ & $\begin{array}{c}\text { Post-test FBSL } \\
(\mathrm{Mg} / \mathrm{dl})\end{array}$ \\
\hline $\mathrm{N}$ & 180 & 180 \\
\hline Mean & 127.02 & 119.78 \\
\hline Median & 126.0 & 121.0 \\
\hline Mode & 120.0 & 140.0 \\
\hline Std deviation & 15.74 & 16.65 \\
\hline Skewness & 0.26 & -0.13 \\
\hline
\end{tabular}

Table 8 . Statistical analysis of height $(\mathrm{Ht})$ in relation to age (Yrs)

\begin{tabular}{|l|c|c|}
\hline & Ht $(\mathrm{m})$ & Age (Yrs) \\
\hline $\mathrm{N}$ & 180 & 180 \\
\hline Mean & 1.63 & 52.44 \\
\hline Median & 1.63 & 51.0 \\
\hline Mode & 1.58 & 51.0 \\
\hline Std deviation & 0.11 & 4.98 \\
\hline Skewness & 0.62 & 0.34 \\
\hline
\end{tabular}

Table 9. Mean and standard deviation of descriptive statistics of pretest and posttest fasting blood sugar level and age group

\begin{tabular}{|l|c|c|c|c|}
\hline $\begin{array}{l}\text { Variable } \\
\text { (mg / dl) }\end{array}$ & $\begin{array}{c}\text { Age group } \\
\text { (Yrs) }\end{array}$ & N & $\begin{array}{c}\text { Mean } \\
\text { (mg/dl) }\end{array}$ & $\begin{array}{c}\text { SD } \\
( \pm)\end{array}$ \\
\hline Fasting Sugar & $40-45$ & 35 & 114 & 4.58 \\
Level & $46-51$ & 45 & 104 & 16.09 \\
(Pre-test) & $52-57$ & 45 & 112.8 & 10.33 \\
& $58-$ above & 55 & 112.1 & 11.25 \\
\hline Fasting sugar & Total & 180 & 111.35 & 10.76 \\
level & $40-45$ & 35 & 97.33 & 10.76 \\
(Post-test) & $46-51$ & 45 & 96.33 & 12.66 \\
& $52-57$ & 45 & 96.6 & 13.15 \\
& $58-$ above & 55 & 100.11 & 9.6 \\
& Total & 180 & 98.25 & 10.71 \\
\hline
\end{tabular}


Table 10. Frequency distribution and percentage representation of the participants

\begin{tabular}{|l|c|c|}
\hline Age group (Yrs) & Frequency & Percent \\
\hline $40-45$ & 35 & 19.44 \\
\hline $46-51$ & 45 & 25 \\
\hline $52-57$ & 45 & 25 \\
\hline $58-$ above & 55 & 35.56 \\
\hline Total & $\mathbf{1 8 0}$ & $\mathbf{1 0 0}$ \\
\hline
\end{tabular}

Table 11. Model summary of the regression analysis of pre-exercise state of the participants

\begin{tabular}{|c|c|c|c|c|}
\hline Model & $\mathrm{R}$ & R-Square & Adjusted R Square & Std Error of the Estimate \\
\hline 1 & $0.822^{\mathrm{a}}$ & 0.676 & 0.657 & 14.09834 \\
\hline
\end{tabular}

Note: a. Predictors: (Constant) Height (M), Pre waist-hip-ratio, Pre Him (cm), Age (yrs), Pre diastolic, Pre weight (Kg), Pre-fasting blood sugar level, Pre BMI, Pre-systolic, pre waist.

Table 12. ANOVAb summary of the regression analysis of pre-exercise state of the participants

\begin{tabular}{|l|c|c|c|c|c|}
\hline Model 1 & Sum of Square & df & Mean Square & F & Sig. \\
\hline Regression & 700027.350 & 10 & 7002.735 & & \\
\hline Residual & 33590.978 & 169 & 198.763 & 35.232 & $0.000^{\text {a }}$ \\
\hline Total & 103618.328 & 179 & & & \\
\hline
\end{tabular}

Note: a. Predictors: (Constant), Height (m), Pre waist-hip-ratio, Pre hip (cm), Age (yrs), Pre diastolic (mmHg), Pre weight (Kg), Pre fasting blood sugar level (mg/dl), Pre systolic (rnmHg), Pre BMI (Kg/rn2), Pre-waist (cm).

b. Dependent variable: Pre RHR = Resting Heart Rate

Table 13. Model summary of the regression analysis of post-exercise state of the participants

\begin{tabular}{|c|c|c|c|c|}
\hline Model & $\mathrm{R}$ & R-Square & Adjusted R Square & Std Error of the Estimate \\
\hline 1 & $0.822^{\mathrm{a}}$ & 0.697 & 0.679 & 13.43234 \\
\hline
\end{tabular}

Note: a. Predictors: (Constant), Post fasting blood sugar level, post BMI, post systolic, age, post diastolic, post hip (cm), post waist-hip-ratio, height (m), post weight $(\mathrm{kg})$, post waist.

Table 14. ANOVAb summary of the regression analysis of post-exercise state of the participants

\begin{tabular}{|l|c|c|c|c|c|}
\hline Model 1 & Sum of Square & df & Mean Square & F & Sig. \\
\hline Regression & 70195.919 & 10 & 7019.592 & & \\
\hline Residual & 30492.281 & 169 & 180.428 & 38.905 & $0.000^{\text {a }}$ \\
\hline Total & 100688.200 & 179 & & & \\
\hline
\end{tabular}

Note: a. Predictors: (Constant), Post fasting blood sugar level, post BMI, Post systolic, Age, Post diastolic, Post hip (cm), Post waist-hip-ratio, Height (rn), Post weight (Kg), Post waist.

b. Dependent variable: Pre RHR

Table 15. Paired samples test of the significance of the difference pre-exercise and post-exercise scores

\begin{tabular}{|c|c|c|c|c|c|c|c|c|}
\hline Variable & Mean & Std & $\begin{array}{c}\text { Std Error } \\
\text { Mean }\end{array}$ & $\begin{array}{c}\text { Paired Differences 95\% } \\
\text { confidence interval of the } \\
\text { difference }\end{array}$ & $\begin{array}{c}\mathrm{t} \\
\text { Significance } \\
\text { (2-tailed) }\end{array}$ \\
\hline $\begin{array}{c}\text { Pair I } \\
\text { Post-pre }\end{array}$ & -847342 & 4.25132 & 0.31687 & -909871 & -7.84813 & -26.74 & 179 & 0.000 \\
\hline
\end{tabular}

